
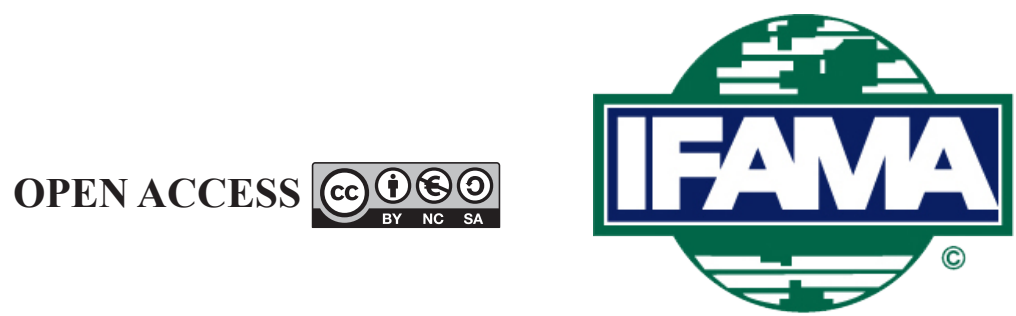

International Food and Agribusiness Management Review

Volume 24, Issue 6, 2021; DOI: 10.22434/IFAMR2020.0138

Received: 24 August 2020 / Accepted: 3 November 2020

Special Issue: IFAMA 2020 symposium

\title{
Keeping the farm business in the family: the case of farm and non- farm family businesses in the midwestern United States \\ RESEARCH ARTICLE
}

\author{
Edeoba W. Edobor ${ }^{\circledR a}$, Renee D. Wiatt ${ }^{\mathrm{b}}$ and Maria I. Marshall ${ }^{\mathrm{c}}$ \\ ${ }^{a}$ Graduate Research Assistant, ${ }^{b}$ Family Business Managment Specialist, ${ }^{c}$ Professor, Purdue Institute for \\ Family Firms, Department of Agricultural Economics, Purdue University, West Lafayette, IN 47906, USA
}

\begin{abstract}
Succession planning is a very crucial aspect of family business continuity. The successful transition of family businesses is especially important for small and medium scale family businesses which constitute the beginning phase of most businesses. This paper explores two critical aspects of succession planning, namely the decision to keep business ownership within the family and the transfer-readiness of family businesses. This study assessed potential correlates of these two constructs using data from small and medium scale farm and non-farm businesses in Midwest US. Results from a probit estimator showed that farm businesses were more likely to be kept within the family $(P<0.01)$. For the full sample, the number of generations involved in daily management, the readiness of the senior management to delegate control, and the owner experience were found to be good correlates of the decision to keep the business within the family. For farms, we also found some correlation between the perception of the business as being successful and the decision to keep the business in the family $(P<0.1)$. Results from the probit and bivariate probit models showed that capital and the number of generations in management are the most consistent correlates of transfer-readiness for the full and farm samples. Finally, we found that female owners of farm businesses were less likely to be ready for business transfers than their male counterparts $(P<0.01)$.
\end{abstract}

Keywords: succession planning, transfer-readiness, small and medium family businesses, farm businesses JEL code: D19, M19, M29, Q12

(1)Corresponding author: eedobor@purdue.edu 


\section{Problem statement}

While there is no universal consensus on the definition of a family business, a recurring theme focuses on ownership and involvement of family in management. According to Poza and Daugherty (2010), a family business is one that: involves ownership control by two or more members of a family; has strategic influence by family members on the management of the business; and exhibits a concern for familial relationships with an emphasis on inter-generational continuity. Family businesses are a crucial part of global economies (Ramadani and Hoy, 2015; Stavrou and Swiercz, 1998) and have a large influence on the United States economy. Different estimates put their contribution to the US gross domestic product between 49 and 57\%, employing about $80 \%$ of the workforce (FEUSA, 2011; Poza and Daugherty, 2010). Despite these advantages, many family businesses do not survive beyond the first generation of family owners. According to the Family Firm Institute, about 70 and $90 \%$ of family businesses do not make it to the second and third generation, respectively (Walsh, 2011). A major reason for this is the lack of adequate transition planning by founding business owners. For example, the 2016 Family Business Survey conducted by PricewaterhouseCoopers (PWC) found that almost half of family-owned businesses do not have a succession plan. The need for a successful business transition is even more dire for small family businesses for several reasons. First, family businesses start as small and medium scale firms, and are therefore the bedrock of the economy. When they are not successfully transitioned, there will be adverse multiplier effects for the larger economy. Secondly, research has shown that where small, family-owned businesses are not properly transitioned, their performance diminishes when larger corporations acquire them due to bureaucracy and a loss of commitment to family and local community values (Sund et al., 2015). Lastly, family businesses are a nexus of social dimensions that comes with kinship and business interests (Danes et al., 2008; Stafford et al., 1999; Taiguri and Davis, 1996). These two factors often lead to internal frictions which are mostly accentuated in small family businesses (Pieper et al., 2013). Hence, there is a need for an informed succession process for small family businesses (Harveston et al., 1997).

Succession planning is a crucial part of family business continuity (Saan et al., 2013). For example, designating a successor gives impetus for business expansion, capital investment and increased output aspirations over the long term (Calus and Huylenbroeck, 2008). This phenomenon is akin to the succession effect identified by Kimhi et al. (1995). While many family business owners recognize these benefits, the reality is that only a few have a plan for the transfer of their businesses. A survey of Iowa family farms found that $60 \%$ of the farmers did not have an estate plan and only $27 \%$ had even identified a successor (Duffy et al., 2006). Similarly, a study of farm operators in California showed that only half had identified a successor (Giraud and Baker, 2005). Previous studies (Calus and Van Huylenbroeck, 2008; De Massis et al., 2008) have suggested that the decision of succession is dependent on socioeconomic characteristics of the business owners or operators such as age, assets, and experience. Other studies have looked at the business characteristics and how they affect the succession decision. However, as alluded to earlier, family businesses are unique in that they combine familial elements with the neo-classical profit-making objective of the firm. When family is integrated with the business, the bonds that are occasioned by familial ties may affect the succession decision since it is often priority to maintain family bonds (Wiatt and Marshall, 2017a). Based on this reasoning, we examined how owner, family and business characteristics impact succession-readiness of business owners as well as their desire to keep the business within the family.

This study expands the family business succession literature in two ways. First, taking into consideration the fact that succession planning is driven by a decision to keep the business within the family, we estimate two probit models to first assess the factors that could drive the business owners' decision to keep the business within the family, and another model to explain drivers of transfer or succession readiness among family business owners. These constructs have not received as much attention in literature as other aspects of succession planning like identification of successors. While most previous research have focused on the factors that affect intra-family succession, there is little or no acknowledgement about how incumbents make decisions on whether or not to carry out business transfers (Boyd et al., 2014). Secondly, we explore the idea that the correlates of these factors can vary across different family businesses. We take advantage 
of our data which covers small family farms and non-farm businesses to make this comparison so as to reveal the industry-specific dynamics at play in family businesses. An additional impetus for this choice is the fact that the Midwest region of the US where this study was carried out is known for its predominantly agricultural economy. Finally, by using variety of econometric methods to assess correlates of succession readiness, we contribute towards the literature while ensuring robustness of our findings.

\section{Literature review}

\subsection{Nature and performance of family businesses}

Family businesses bear some unique attributes that separates them from all other businesses. These attributes include their combination of family ties, socioeconomic wealth priorities and profit making. The extent to which the business combines these dimensions also differentiates family firms from one another (Miller et al., 2013; Memili and Misra, 2015). These differences which explain the goals and conduct of family businesses have also been used to explain their performance. The relationship between the nature of family businesses has opened up a stream of research with some recent studies of US firms suggesting that family businesses which are publicly traded usually perform better than their non-family business counterparts (Miller et al., 2007). An oft-stated theoretical underpinning for this observation is the difference between the principal-principal paradigm of family businesses as opposed to the principal-agent structure of non-family businesses (Memli and Misra, 2015). While managers of family business will tend to be more altruistically aligned with the goals of their businesses, in non-family businesses there is usually the problem of incentive misalignment. One will therefore expect that with higher levels of family involvement, family businesses will perform better. Martin-Reyna and Duran-Encalanda (2015) studied public firms in Mexico and found that businesses where the ownership is concentrated within family members exhibited higher performance levels. Using panel data of US firms, Memli and Misra (2015) showed a U-shaped relationship between family involvement and firm performance. This suggests a range where there is a negative performance return to family involvement. Miller et al. (2013) reported that greater family involvement is related to strategic conformity which also relates positively to higher returns on assets.

\subsection{Succession planning in family businesses}

Succession planning is a very important research area mostly because it is the most often cited factor underlying failures in business continuity (Boyd et al., 2014). Moreover, the need for a transfer or succession process can be very abrupt e.g. in the case where incumbents suffer sudden death, or health problems, and as such must be pre-planned (Musselman, 2015). The succession decision is a very critical, and often difficult one (Ramadani and Hoy, 2015). The succession process often initiates and requires strategic planning. A good succession process therefore requires that the incumbents must be willing to give up responsibility and authority, and the successor must be ready to accept control of the business (De Massis et al., 2008). While most previous research have focused on the factors that affect intra-family succession, there is little or no acknowledgement about how incumbents make decisions on whether or not to carry out business transfers (Boyd et al., 2014).

\section{Conceptual model}

The theoretical underpinning for this research is the classical three circle model developed by Taiguri and Davis (1996). This model argues for three dimensions of the family business with overlap between the dimensions. The dimensions which include ownership, business, and family show the distinct interest groups in a family business. Apart from the family dimension, the others might consist of non-family members as shown in Figure 1. Each of these family business dimensions come with unique characteristics that have implications for the functioning of the business including the succession process. 
The family dimension, for example consists of active family members including young members who are just entering the business and learning the ropes from the incumbent generation. These two generations will have to learn to work together with a view to handing over the reins of the business to the younger generation (Lissoni et al., 2010). This dimension includes family owners as well as non-members. The owner dimension which consists of family and non-family is of utmost interest in the succession planning process. Interestingly, in the development of the model it was the last dimension added to the previously held dual model consisting of only the family and business dimensions (Barrett, 2014). This dimension is typically characterized by a progression from a controlling owner to a sibling partnership, then to a cousin consortium (Lissoni et al.,2010). The business dimension represents the management dimension of the family business. These are the members of the business responsible for the operational parts of the business and daily decision making. This dimension includes family and non-family members.

The three-circle model has been used in previous studies to understand family business succession and life-cycle progression for its theoretical elegance and practicality (for example Lissoni et al., 2010; Warnar, 2012). We therefore abstract from this model to develop variables in each of these three dimensions. We argue for the relevance of these variables in explaining our variables of interest namely transfer readiness and the decision to keep the business within the family. The elements of these dimensions are shown in Figure 1

\section{Methods}

\subsection{Data}

This study was based on the 2012 Intergenerational Farm and Non-Farm Family Business Survey which was a 30 minutes survey of rural small and medium family businesses in selected parts of the Midwest United States. Respondents for the study was drawn from a list of 2,163 small family businesses in Illinois, Indiana, Michigan and Ohio who were registered in the Food Industry Market Maker. Interviews were conducted by the University of Wisconsin Survey Center from April 2011 to February 2012. To be eligible for this study as a family business, businesses had to satisfy at least one of the following criteria: At least one other family member beside the respondent must have ownership interest in the business ( $86 \%$ of the sample); at least one other member of the respondent's family worked at least part-time in the family business (92\%); the respondent inherited the business (18\%); the respondent planned to transfer the business to a family member $(55 \%)$. Based on this criterion, the final sample consisted of 736 family businesses representing an overall response rate of $34 \%$. After further examination of responses only 547 valid observations were used for our analysis. The final observations consisted of 378 (69.10\%) farming and $169(30.90 \%)$ non-farming businesses.

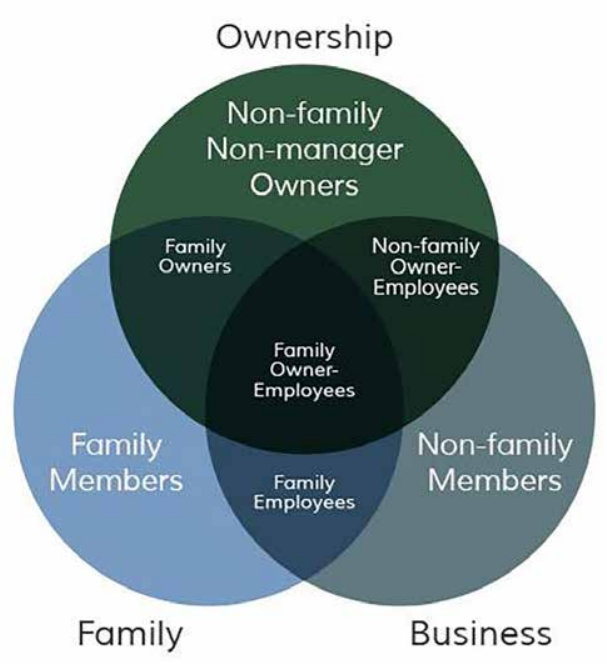

Figure 1: Three circle model (Taiguri and Davis, 1996). 


\subsection{Empirical model}

Scholars such as Glauben et al. (2004) and Lange et al. (2011) have used a probit model in their estimation of factors that affected likelihood of farm succession, and transfer decision, respectively. Following this convention, we estimated probit models of the form

$$
\mathrm{P}(\mathrm{Y}=1)=\alpha+\beta_{\mathrm{a}} \mathrm{W}+\beta_{\mathrm{b}} \mathrm{X}+\beta_{\mathrm{c}} \mathrm{Z}+\varepsilon
$$

where $\mathrm{Y}$ is the dependent variable of interest i.e. the decision to keep the business in the family $\left(\mathrm{Y}_{\mathrm{d}}\right)$ or the transfer readiness $\left(\mathrm{Y}_{\mathrm{r}}\right)$. This variable is implemented as a binary indicator taking the value 1 where the business is ready for immediate transfer or the owner plans to keep the business within the family and 0 otherwise. $\mathrm{W}$ is a vector of business characteristics, $\mathrm{X}$ is a vector of owner characteristics, and $\mathrm{Z}$ is a vector of family characteristics. The model was estimated for the full sample, farms only, and non-farms. $\alpha$ is a constant representing the intercept, and $\varepsilon$ represents the error term. As part of the family characteristics we include the FB-BRAG measure developed by Wiatt and Marshall (2017b) to consolidate the family and business dimensions of family businesses into a single assessment. The FB-BRAG (acronym for family/ business balance, resolve, adaptability and growth) is a modification of the APGAR (acronym for adaptability, partnership, growth, affection and resolve) assessments developed by Smilkstein (1982). Finally, we also abstract from Mincer (1993) by computing an experience index using owner age and educational level.

To estimate the model explaining succession-readiness of the family businesses we had to make some econometric adjustments as follows. First, anecdotally we understand that the transfer-readiness of a business depends in part on whether or not the owner decides to keep the business in the family. Moreover, transferreadiness also depends on the family, business and owner characteristics that were earlier outlined. This introduces endogeneity as a result of the simultaneity between the decision to keep the business in the family, and the succession readiness of the business. We therefore correct this by using a variety of techniques. First, we estimate two probit models as specified earlier with or without the owners' decision to keep the business in the family as an independent variable, and succession readiness $\left(\mathrm{Y}_{\mathrm{r}}\right)$ as the dependent variable. To deal with the issue of simultaneity, as proposed by Li et al. (2016), we implemented a bivariate probit model instrumenting for the decision to keep the business in the family. The instrument used was a dummy variable indicating whether the business has at least one other family member with ownership interest. Our assumption here is that this will have an influence on the decision of the business owner(s) to keep it in the family, especially out of legacy considerations. This variable should not have a direct causal effect on the transfer-readiness of the business except the owner(s) have decided on whether to keep the business. Moreover, this variable is exogenous and is not determined in the regression. The bivariate probit model is specified as follows:

$$
\begin{aligned}
& Y_{r}^{*}=\sigma+\phi_{\mathrm{i}} \mathrm{Y}_{\mathrm{d}}+\phi_{\mathrm{j}} \mathrm{W}+\phi_{\mathrm{k}} \mathrm{X}+\phi_{\mathrm{l}} \mathrm{Z}+\varepsilon_{2} \\
& Y_{d}^{*}=\omega+\gamma_{\mathrm{q}} \mathrm{W}+\gamma_{\mathrm{r}} \mathrm{X}+\gamma_{\mathrm{s}} \mathrm{Z}+\gamma_{\mathrm{t}} \mathrm{G}+\varepsilon_{1}
\end{aligned}
$$

Where given that the indicator is defined by a function $\mathrm{f}($.

$$
Y_{r}=f\left(Y_{r}>0\right) \text { and } Y_{d}=f\left(Y_{d}>0\right)
$$

The bivariate model also assumes that $\varepsilon_{1}$ and $\varepsilon_{2}$ are drawn from a standard bivariate normal distribution with zero means, variances equal 1 , and a correlation coefficient $\rho$ such that

$$
\left(\varepsilon_{1}, \varepsilon_{2}\right) \sim \mathrm{N}_{2}\left(\begin{array}{ccc}
0 & 1 & \rho \\
0 & \rho & 1
\end{array}\right)
$$

In this model, the vectors $\mathrm{W}, \mathrm{X}, \mathrm{Z}$ and $\mathrm{Y}_{\mathrm{d}}$ are as indicated in Equation $1 . \mathrm{Y}_{\mathrm{r}}$ is an indicator of the succession readiness of the business, while $\mathrm{G}$ is a dummy variable which equals 1 if another family member has some 
ownership interest in the business, and 0 otherwise. $\varepsilon_{1}$ and $\varepsilon_{2}$ are error terms. The bivariate probit also serves as a robustness check for the other earlier estimates. Table 1 identifies the variables and definitions used in the model.

\section{Results and discussion}

The study results in Table 2 showed that $237(43.32 \%)$ of the total respondents were prepared for immediate management succession. When the primary business purpose is considered, we find that $44.83 \%(169)$ of the farm businesses were prepared for immediate management succession compared with $40.24 \%$ (68) of the

Table 1. Study variables and definitions.

\begin{tabular}{|c|c|}
\hline Variable & Definition \\
\hline \multicolumn{2}{|l|}{ Dependent variables } \\
\hline Keep business in family & $\begin{array}{l}=1 \text { if distribution of the business to the next generation includes selling or } \\
\text { giving the business to family successors; }=0 \text { if business will be sold to someone } \\
\text { outside of the family or liquidated }\end{array}$ \\
\hline Transfer readiness & $=1$ if owner is ready for immediate business transfer; $=0$ otherwise \\
\hline \multicolumn{2}{|l|}{ Business characteristics } \\
\hline Profit below $\$ 50,000$ & $=1$ if the business made a profit below $\$ 50,000$ in $2010 ;=0$ otherwise \\
\hline Profit of $\$ 50,000$ and above & $=1$ if the business made a profit above $\$ 50,000$ in $2010 ;=0$ otherwise \\
\hline Co-preneurship & $\begin{array}{l}=1 \text { if the owner's spouse is involved in the daily management of the business; } \\
=0 \text { otherwise }\end{array}$ \\
\hline Successful business & $\begin{array}{l}=1 \text { if business owner says that the business is somewhat successful or } \\
\text { successful; }=0 \text { otherwise }\end{array}$ \\
\hline Primary business purpose & $=1$ if non-farm family businesses; $=0$ if the business is a family farm \\
\hline Capital & $\begin{array}{l}=1 \text { if there is enough capital or money to implement a transfer of the business; } \\
=0 \text { otherwise }\end{array}$ \\
\hline Business priority & $\begin{array}{l}=1 \text { otherwise i.e. keeping familial connections, }=0 \text { if the most important } \\
\text { business goal is profit or positive reputation with customers }\end{array}$ \\
\hline LLC, Corporation, or Trust & $\begin{array}{l}=1 \text { if the business is organized as an LLC, corporation, or trust; }=0 \text { if business } \\
\text { is solely owned or a partnership }\end{array}$ \\
\hline \multicolumn{2}{|l|}{ Family characteristics } \\
\hline Regularly discuss goals & $\begin{array}{l}=1 \text { if the family discusses business goals on a quarterly basis or more } \\
\text { frequently; }=0 \text { otherwise }\end{array}$ \\
\hline Estate plan discussion & $\begin{array}{l}=1 \text { if the family has ever met with an accountant, financial planner, lawyer, or } \\
\text { business consultant to discuss estate planning; }=0 \text { otherwise }\end{array}$ \\
\hline Senior generation ready & $\begin{array}{l}=1 \text { if the senior generation is already delegating management to heirs or } \\
\text { successors or is very open to do so; }=0 \text { otherwise }\end{array}$ \\
\hline Generations in management & $\begin{array}{l}\text { =number of generations of family members involved in the day to day } \\
\text { management of the business }\end{array}$ \\
\hline FB-BRAG & $\begin{array}{l}\text { 16-point Likert scale of how functional a family and business interact and work } \\
\text { with one another }(0=\text { most dysfunctional and } 16=\text { most functional })\end{array}$ \\
\hline \multicolumn{2}{|l|}{ Owner characteristics } \\
\hline Experience & $=$ business owner's age in 2010 less years of education obtained \\
\hline Female & $=1$ if business owner is female; $=0$ otherwise \\
\hline Married & $=1$ if the business owner is married; $=0$ otherwise \\
\hline Constant & $=$ intercept \\
\hline \multicolumn{2}{|l|}{ Instrument } \\
\hline Ownership interest & $\begin{array}{l}=1 \text { if the business has at least one other family member with ownership interest; } \\
=0 \text { otherwise }\end{array}$ \\
\hline
\end{tabular}


Table 2. Descriptive statistics. ${ }^{1}$

\begin{tabular}{lccc}
\hline Variable & Total (\%) & Farms (\%) & Non-farms (\%) \\
\hline Keep business in family & $329(60.15)$ & $243(64.29)$ & $86(50.89)$ \\
Transfer readiness & $237(43.32)$ & $169(44.83)$ & $68(40.24)$ \\
Profit below \$50,000 & $397(72.58)$ & $277(73.28)$ & $120(71.01)$ \\
Profit of \$50,000 and above & $150(27.42)$ & $101(26.72)$ & $49(28.99)$ \\
Co-preneurship & $366(66.91)$ & $260(68.78)$ & $106(62.72)$ \\
Successful business & $501(91.59)$ & $348(92.06)$ & $153(90.53)$ \\
Capital & $367(67.09)$ & $254(67.20)$ & $113(66.86)$ \\
Business priority & $207(37.84)$ & $152(40.21)$ & $55(32.54)$ \\
LLC, Corporation, or Trust & $206(37.66)$ & $125(33.07)$ & $81(47.93)$ \\
Regularly discuss goals & $333(60.88)$ & $220(58.20)$ & $113(66.86)$ \\
Estate plan discussion & $334(61.06)$ & $227(60.05)$ & $107(63.31)$ \\
Senior generation ready & $159(29.07)$ & $108(28.57)$ & $51(30.18)$ \\
Female & $215(39.31)$ & $152(40.21)$ & $63(37.28)$ \\
Married & $488(89.21)$ & $335(88.62)$ & $153(90.53)$ \\
Ownership interest & $480(87.75)$ & $333(88.10)$ & $147(86.98)$ \\
\hline Generations in management & 1.56 & 1.60 & 1.47 \\
FB-BRAG & 10.34 & 10.39 & 10.21 \\
Experience & 44.84 & 45.05 & 44.36 \\
\hline
\end{tabular}

${ }^{1}$ For all binary variables, numbers indicated represent instances where the dummy variable $=1$ and percentages are indicated in parentheses. Otherwise, numbers indicate means of the variables.

non-farm businesses. Also, 329 (60.15\%) of the total respondents have decided or planned to keep the business within the family. When disaggregated by primary business purpose, $64.29 \%$ (243) of the farm businesses planned to keep their businesses in their families compared to $50.89 \%$ (86) of the non-farm businesses.

Table 3 presents results of the probit model explaining possible drivers of owners' decision to keep the business within the family. Model estimates for the full sample show that the primary business purpose, the number of generations in daily management, and owner experience were the most correlated with the owners' decision to keep the business within the family, all being significant at the $1 \%$ significance level. The delegation of management control to the successor by the incumbent, as well as the business priority were also found to be important correlates of owners' desire to keep the business within the family at the 5\% significance level. The analysis of the marginal effects (Table 4) showed that the probability that owners will keep a business in the family decreases by about $13.1 \%$ when the business is a non-farming one. Where the business' primary priority is to keep family ties, the probability that the owners planned to keep the business within the family increased by $9 \%$. The delegation of management to the successor by the incumbent was shown to increase the likelihood that the business owner will keep the business in the family by $12.4 \%$. The positive correlation with number of generations in daily management, as well as delegation of management control is expected where businesses plan to keep their businesses within the family. These processes serve as means to orient the next generation and help ease the eventual transfer of the businesses. However, the negative correlation of experience is less intuitive. An explanation may be that an owner who has spent a long time operating the business, particularly a farm business, without relinquishing control may have difficulties transferring the business to family members.

The strong correlation between the primary business purpose with the owner's decision to keep the family business motivated our decision to carry out further industry-specific analysis which is also reported in Table 3. Just as was observed with the full sample, these results showed that the probability that business owners keep the business within the family increased with the number of generations involved in daily management and decreased with the years of owners' experience at $1 \%$ significance level. For the farm sample, other 
Table 3. Probit model estimation showing correlates of decision to keep the business within the family. ${ }^{1}$

\begin{tabular}{lllc}
\hline $\begin{array}{l}\text { Dependent variable: Decision to keep } \\
\text { the business within the family }\end{array}$ & $\begin{array}{l}\text { Full sample } \\
(\mathbf{n = 5 4 7 )}\end{array}$ & $\begin{array}{l}\text { Farms only } \\
(\mathbf{n = 3 7 8 )}\end{array}$ & $\begin{array}{l}\text { Non-farm businesses } \\
(\mathbf{n = 1 7 0 )}\end{array}$ \\
\hline Profit of $\$ 50,000$ and above & $0.130(0.140)$ & $0.107(0.170)$ & $0.426^{*}(0.258)$ \\
Co-preneurship & $0.041(0.139)$ & $0.123(0.165)$ & $-0.240(0.250)$ \\
Successful business & $0.114(0.207)$ & $0.418^{*}(0.249)$ & $-0.596(0.401)$ \\
Primary business purpose & $-0.342^{* * *}(0.124)$ & & \\
Capital & $0.115(0.125)$ & $0.166(0.149)$ & $0.018(0.259)$ \\
Business priority & $0.237 *(0.125)$ & $0.162(0.148)$ & $0.347(0.269)$ \\
LLC, Corporation, or Trust & $0.178(0.130)$ & $0.247(0.159)$ & $-0.011(0.258)$ \\
Regularly discuss goals & $0.008(0.125)$ & $0.120(0.149)$ & $-0.013(0.243)$ \\
Estate plan discussion & $0.112(0.125)$ & $0.211(0.150)$ & $-0.005(0.245)$ \\
Senior generation ready & $0.338 * *(0.135)$ & $0.116(0.165)$ & $0.821 * * *(0.258)$ \\
Generations in management & $0.614^{* * *}(0.122)$ & $0.542 * * *(0.146)$ & $0.887 * * *(0.202)$ \\
FB-BRAG & $0.017(0.028)$ & $0.008(0.033)$ & $0.073(0.056)$ \\
Experience & $-0.022 * * *(0.005)$ & $-0.020 * * *(0.006)$ & $-0.028^{* * *}(0.108)$ \\
Female & $-0.072(0.118)$ & $-0.038(0.145)$ & $-0.059(0.220)$ \\
Married & $-0.072(0.211)$ & $-0.274(0.233)$ & $0.476(0.376)$ \\
Intercept & $-0.211(0.472)$ & $-0.354(0.540)$ & $-0.938(0.956)$ \\
\hline
\end{tabular}

$1 *, * *$, and $* * *$ denote statistical significance at the 10,5 and $1 \%$ levels, respectively. Standard errors in parentheses.

Table 4. Marginal effects of correlates of decision to keep the business within the family (probit model). ${ }^{1}$

\begin{tabular}{llcc}
\hline $\begin{array}{l}\text { Dependent variable: decision to keep } \\
\text { the business within the family }\end{array}$ & $\begin{array}{l}\text { Full sample } \\
(\mathbf{n}=\mathbf{5 4 7})\end{array}$ & $\begin{array}{l}\text { Farms only } \\
(\mathbf{n = 3 7 8 )}\end{array}$ & $\begin{array}{l}\text { Non-farm businesses } \\
(\mathbf{n = 1 7 0 )}\end{array}$ \\
\hline Profit of $\$ 50,000$ and above & $0.049(0.052)$ & $0.039(0.060)$ & $0.167(0.098)$ \\
Co-preneurship & $0.016(0.053)$ & $0.045(0.062)$ & $-0.095(0.098)$ \\
Successful business & $0.044(0.081)$ & $0.160^{*}(0.098)$ & $-0.223(0.135)$ \\
Primary business purpose & $-0.131^{* * *}(0.048)$ & & \\
Capital & $0.044(0.048)$ & $0.061(0.055)$ & $0.007(0.103)$ \\
Business priority & $0.090^{*}(0.046)$ & $0.058(0.053)$ & $0.137(0.104)$ \\
LLC, Corporation, or Trust & $0.067(0.048)$ & $0.088(0.055)$ & $-0.005(0.103)$ \\
Regularly discuss goals & $0.003(0.047)$ & $0.043(0.055)$ & $-0.005(0.097)$ \\
Estate plan discussion & $0.043(0.048)$ & $0.078(0.555)$ & $0.002(0.097)$ \\
Senior generation ready & $0.124 * *(0.048)$ & $0.416(0.057)$ & $0.310^{* * *}(0.089)$ \\
Generations in management & $0.234^{* * *}(0.045)$ & $0.194 * * *(0.517)$ & $0.353 * * *(0.080)$ \\
FB-BRAG & $0.006(0.107)$ & $0.003(0.012)$ & $0.029(0.022)$ \\
Experience & $-0.008^{* * *}(0.002)$ & $-0.007 * * *(0.002)$ & $-0.011^{* * *}(0.004)$ \\
Female & $-0.027(0.045)$ & $-0.014(0.053)$ & $-0.024(0.088)$ \\
Married & $-0.027(0.078)$ & $-0.095(0.075)$ & $0.187(0.141)$ \\
\hline $1 * * *$, and $* * *$ denote statistical significance at the 10,5 and $1 \%$ levels, respectively. Standard errors in parentheses.
\end{tabular}

variables which were found to be correlated with business owner's decision to keep the business in the family included business success $(P<0.1)$. The probability that the owner would keep the business in the family increased where the business is deemed by the owner to be successful. For the non-farm businesses, the other important correlates were profits of $\$ 50,000$ and above $(P<0.1)$, and readiness of the senior generation to delegate management to the younger generation $(P<0.05)$. These results suggest that when farms were perceived to be successful, they were more likely to be kept within the family, suggesting a desire to keep the family legacy going. With non-farm businesses, however, the increased profit result suggests that most 
non-farm family businesses sought ownership interest from outside the family to be able to manage the expansion. Also, most small family farms tend to depend on off-farm income.

Table 5 shows the full sample results of the probit and bivariate probit estimates for transfer readiness. Capital $(P<0.01)$ and the number of generations in daily management were found to consistently had a positive correlation with the transfer readiness of the businesses irrespective of the estimator used. These results corroborate findings by Wiatt and Marshall (2017a) who found similar correlations for the probability that small businesses have identified successors. Involving more generations in the daily management of the business enables the preparation of likely successors and is therefore a strong precursor of transfer-readiness. There is also a strong role for capital as succession transfers require enough capital for implementation. Also, generational transfer also means that enough capital must have been acquired by each succeeding generation (Mishra et al., 2010).

The analysis of the marginal effect (Table 6) shows that owners' decision to keep the business in the family increased their transfer-readiness by about $18 \%$. The availability of sufficient capital for the transfer process increased the probability of transfer-readiness by about $19 \%$ irrespective of if the model was controlled for owner's decision to keep the business within the family. Where the decision to keep the business in the family was controlled for, senior generation readiness was found to increase transfer-readiness by $11 \%$. Similarly, having an additional generation of the family in management increased the probability of transfer-readiness by $11 \%$. On the other hand, when transfer readiness is controlled for, the marginal effects for senior generation readiness and generations in management reduces to $9 \%$ and $7 \%$ respectively. Finally, being married had a negative marginal effect of about $20 \%$ in both models, while experience had a positive marginal of about $0.5 \%$.

Table 5. Probit and bivariate probit estimation of the transfer-readiness of family businesses $(n=547){ }^{1}$

\begin{tabular}{|c|c|c|c|c|}
\hline & Probit model $^{2}$ & Probit model $^{2}$ & Bivariate probit ${ }^{3}$ & Bivariate probit $^{2}$ \\
\hline $\begin{array}{l}\text { Owners' decision to keep the } \\
\text { business within the family }\end{array}$ & & $0.461 * * *(0.129)$ & & $-0.227(0.806)$ \\
\hline Ownership interest & & & $0.445 * *(0.208)$ & \\
\hline Profit of $\$ 50,000$ and above & $0.046(0.134)$ & $0.012(0.133)$ & $0.170(0.148)$ & $0.055(0.143)$ \\
\hline Co-preneurship & $-0.151(0.134)$ & $-0.146(0.136)$ & $-0.001(0.143)$ & $-0.133(0.135)$ \\
\hline Successful business & $0.234(0.214)$ & $0.217(0.218)$ & $0.117(0.213)$ & $0.223(0.210)$ \\
\hline Primary business purpose & $-0.111(0.129)$ & $-0.057(0.131)$ & $-0.341 * * *(0.124)$ & $-0.137(0.157)$ \\
\hline Capital & $0.518 * * *(0.127)$ & $0.506^{* * *}(0.128)$ & $0.091(0.124)$ & $0.503 * * *(0.129)$ \\
\hline Business priority & $0.103(0.121)$ & $0.069(0.123)$ & $0.204(0.127)$ & $0.124(0.134)$ \\
\hline LLC, Corporation, or Trust & $0.034(0.124)$ & $0.011(0.125)$ & $0.148(0.130)$ & $0.049(0.127)$ \\
\hline Regularly discuss goals & $0.144(0.121)$ & $0.140(0.122)$ & $-0.063(0.125)$ & $0.135(0.120)$ \\
\hline Estate plan discussion & $0.136(0.123)$ & $0.122(0.124)$ & $0.001(0.125)$ & $0.141(0.123)$ \\
\hline Senior generation ready & $0.278 * *(0.129)$ & $0.232 *(0.129)$ & $0.357^{* * *}(0.137)$ & $0.297 * *(0.142)$ \\
\hline Generations in management & $0.280 * * *(0.089)$ & $0.190 * *(0.091)$ & $0.601 * * *(0.120)$ & $0.312 *(0.161)$ \\
\hline FB-BRAG & $-0.002(0.028)$ & $-0.007(0.028)$ & $0.017(0.029)$ & $0.001(0.03)$ \\
\hline Experience & $0.013 * * *(0.005)$ & $0.016^{* * *}(0.005)$ & $-0.021 * * *(0.005)$ & $0.010(0.009)$ \\
\hline Female & $-0.172(0.121)$ & $-0.176(0.122)$ & $-0.053(0.118)$ & $-0.179(0.120)$ \\
\hline Married & $-0.511 * *(0.202)$ & $-0.522 * *(0.206)$ & $-0.107(0.220)$ & $-0.510^{* *}(0.212)$ \\
\hline Intercept & $-1.384 * * *(0.474)$ & $-1.56^{* * * *}(0.488)$ & $-0.477(0.501)$ & $-1.220 *(0.650)$ \\
\hline
\end{tabular}


Table 6. Marginal effects for the probit estimation of the transfer-readiness of all family businesses $(\mathrm{n}=547){ }^{1}$

\begin{tabular}{lcc}
\hline & Probit model $^{2}$ & Probit model $^{2}$ \\
\hline Owners' decision to keep the business within the family & & $0.178 * * *(0.048)$ \\
Ownership interest & & $0.005(0.052)$ \\
Profit of $\$ 50,000$ and above & $0.018(0.053)$ & $-0.057(0.054)$ \\
Co-preneurship & $-0.060(0.053)$ & $0.083(0.081)$ \\
Successful business & $0.089(0.080)$ & $-0.022(0.051)$ \\
Primary business purpose & $-0.043(0.050)$ & $0.193 * * *(0.047)$ \\
Capital & $0.197 * * *(0.046)$ & $0.027(0.048)$ \\
Business priority & $0.040(0.048)$ & $0.004(0.048)$ \\
LLC, Corporation, or Trust & $0.013(0.049)$ & $0.055(0.047)$ \\
Regularly discuss goals & $0.056(0.047)$ & $0.048(0.048)$ \\
Estate plan discussion & $0.053(0.048)$ & $0.091 *(0.051)$ \\
Senior generation ready & $0.109 * *(0.051)$ & $0.074 * *(0.036)$ \\
Generations in management & $0.109 * * *(0.035)$ & $-0.003(0.011)$ \\
FB-BRAG & $-0.001(0.011)$ & $0.006 * * *(0.002)$ \\
Experience & $0.005 * * *(0.002)$ & $-0.069(0.047)$ \\
Female & $-0.067(0.047)$ & $-0.206 * * *(0.079)$ \\
Married & $-0.202 * * *(0.078)$ & \\
\hline 1 * **, and *** denote statistical significance at the 10,5 and $1 \%$ levels, respectively. Standard errors in parentheses.
\end{tabular}

Marital status had a consistently negative correlation with transfer-readiness in all the models, while experience showed a positive correlation. While the result for marital status is not as expected, it follows that with more experience, the owner-operator(s) are more familiar with the business operations and would be better prepared to implement a transfer to successors. The openness of the incumbent generation to delegate control was also found to be positively associated with transfer-readiness. This finding buttresses the assertions by scholars such as Venter et al. (2005) that owner-managers must be open to hand over responsibility for successful implementation of transfers. As expected, the decision to keep the business within the family was positively correlated with transfer-readiness. However, when instrumented by ownership interest, there was a negative though insignificant correlation. The results for the probit model in Equation 1 were also robust to those of the bivariate probit model in column 3 of Table 5. We found that the primary business purpose was also negatively corelated with the decision to keep the business in the family implying that farm businesses were more likely to be kept in the family than non-farming businesses. Also, the openness of the incumbent to delegate authority, as well as the number of generations involved in daily management were found to be strongly correlated with the decision to keep the business in the family. Experience was also found to be negatively related with the decision to keep the business.

The probit and bivariate probit models were used to estimate correlates of the transfer-readiness of the farm businesses only. The results are presented in Table 7 with only the final bivariate probit model reported. These results show that capital, experience, the readiness of the senior generation to delegate control and numbers of generations in management status were positively correlated with transfer readiness. However, women and married owners were found to be less likely to be ready for transfers. This result might be confirmatory of some of the challenges faced by women farm owners. Studies have shown that while women play a critical role in US agriculture, they earn less, have smaller holdings and face more institutional barriers than their male counterparts (Moon, 2019). These factors play a role in the transfer process and may adversely impact transfer-readiness. The observed relationship between marital status and both dependent variables can be understood through the fact that with married couples, the family business may be closely tied to marital wellbeing, and this might impact the willingness of the couples to relinquish the business to the next generation. Wiatt et al. (2019) had shown that couples especially those who manage their businesses together 
Table 7. Probit and bivariate probit estimation of the transfer-readiness of family farms $(n=377) .{ }^{1}$

\begin{tabular}{lccc}
\hline & Probit model & Probit model $^{2}$ & Bivariate probit $^{2}$ \\
\hline Owners' decision to keep the business & & $0.491 * * *(0.162)$ & $0.423(1.070)$ \\
within the family & & & $-0.137(0.179)$ \\
Profit of $\$ 50,000$ and above & $-0.103(0.171)$ & $-0.141(0.170)$ & $-0.178(0.173)$ \\
Co-preneurship & $-0.178(0.167)$ & $-0.181(0.168)$ & $0.179(0.325)$ \\
Successful business & $0.260(0.278)$ & $0.169(0.280)$ & $0.613 * * *(0.167)$ \\
Capital & $0.634 * * *(0.160)$ & $0.610 * * *(0.162)$ & $-0.009(0.159)$ \\
Business priority & $0.008(0.147)$ & $-0.013(0.148)$ & $-0.046(0.170)$ \\
LLC, Corporation, or Trust & $-0.024(0.156)$ & $-0.051(0.156)$ & $0.038(0.153)$ \\
Regularly discuss goals & $0.068(0.148)$ & $0.036(0.150)$ & $0.141(0.180)$ \\
Estate plan discussion & $0.161(0.154)$ & $0.136(0.157)$ & $0.218(0.167)$ \\
Senior generation ready & $0.235(0.161)$ & $0.216(0.162)$ & $0.442 *(0.210)$ \\
Generations in management & $0.515 * * *(0.116)$ & $0.431 * * *(0.115)$ & $-0.022(0.035)$ \\
FB-BRAG & $-0.019(0.034)$ & $-0.023(0.034)$ & $0.016 *(0.0)$ \\
Experience & $0.014 * *(0.006)$ & $0.017 * * *(0.006)$ & $-0.494 * * *(0.154)$ \\
Female & $-0.474 * * *(0.154)$ & $-0.494 * * *(0.154)$ & $-0.925 * * *(0.250)$ \\
Married & $-0.936 * * *(0.236)$ & $-0.920 * * *(0.241)$ & $-1.167 *(0.718)$ \\
Intercept & $-1.063(0.572)$ & $-1.190 * *(0.583)$ &
\end{tabular}

$1 *, * *$, and $* * *$ denote statistical significance at the 10,5 and $1 \%$ levels, respectively. Standard errors in parentheses.

2 Dependent variable: transfer readiness.

tend to see those businesses as a joint-retirement plan, and therefore usually look to exit the business jointly thus delaying the transfer process until retirement.

Table 8 shows the marginal effects for the probit estimation of the transfer-readiness of farm businesses only. The results show that owners' decision to keep the business within the family increases the probability of transfer-readiness by $19 \%$. The presence of requisite capital also increases the probability of transfer-readiness

Table 8. Marginal effects for the probit estimation of the transfer-readiness of farm family businesses $(\mathrm{n}=377) .{ }^{1}$

\begin{tabular}{lcc}
\hline & Probit model $^{2}$ & Probit model $^{2}$ \\
\hline Owners' decision to keep the business within the family & & $0.190 * * *(0.060)$ \\
Profit of $\$ 50,000$ and above & $-0.041(0.067)$ & $-0.055(0.066)$ \\
Co-preneurship & $-0.071(0.066)$ & $-0.072(0.067)$ \\
Successful business & $0.100(0.104)$ & $0.066(0.107)$ \\
Capital & $0.242 * * *(0.057)$ & $0.233^{* * *}(0.058)$ \\
Business priority & $0.003(0.058)$ & $-0.005(0.058)$ \\
LLC, Corporation, or Trust & $-0.009(0.061)$ & $-0.020(0.061)$ \\
Regularly discuss goals & $0.027(0.059)$ & $0.014(0.811)$ \\
Estate plan discussion & $0.063(0.060)$ & $0.054(0.062)$ \\
Senior generation ready & $0.093(0.064)$ & $0.085(0.064)$ \\
Generations in management & $0.203 * * *(0.046)$ & $0.170 * * *(0.045)$ \\
FB-BRAG & $-0.007(0.013)$ & $-0.009(0.013)$ \\
Experience & $0.005 * *(0.002)$ & $0.007 * * *(0.002)$ \\
Female & $-0.187 * *(0.058)$ & $-0.192 * * *(0.058)$ \\
Married & $-0.352^{* * *(0.076)}$ & $-0.347 * *$ s $(0.078)$ \\
\hline
\end{tabular}

$1 *, * *$, and $* * *$ denote statistical significance at the 10,5 and $1 \%$ levels, respectively. Standard errors in parentheses.

2 Dependent variable: transfer readiness. 
by 24 and $23 \%$ when we do not control for, and when we control for the decision to keep the business in the family respectively. Like in the full sample, being married also reduced the probability of transfer readiness by about $35 \%$ in both models. Finally, being a female owner reduced the probability of transfer-readiness by about $19 \%$ in both models.

\section{Conclusions and managerial implications}

In this study, we have looked at the effect of owner, business, and family characteristics on two key succession variables namely: the decision to keep the family business in the family, and the transfer readiness of the business owners. We also explored the possibility that this influence will differ based on the primary purpose of the business. The results show that farm businesses are more likely to be kept within the family than non-farming ones. Based on this finding, we carry out an industry-specific analysis by dividing the sample into farm and non-farm businesses. The results show that when farms are perceived to be successful, they are more likely to be kept within the family, suggesting a desire to keep the family legacy going through the business. With non-farm businesses, however, the increased profit result suggests that most non-farm businesses seek ownership interest from outside the family to be able to manage the expansion. Also, using different econometric methods, we estimated a model for correlates of transfer readiness for the full sample and for the farm sample. We found that capital, experience, delegation of control by the senior generation and the number of generations in daily management were positively correlated with transfer readiness among business owners. Finally, the results show that female business owners were less likely to be prepared for immediate business transfer.

Our result of women-owned businesses being less prepared for business transfer implies that pointed planning and intervention for these businesses is crucial. We recommend that women-owned small and medium farm businesses be given more support by advisors. Moreover, deliberate action should be taken by businesses supplied by farms to ensure the inclusion of women-owned farms. Increased income this way can play a big role in ensuring business continuity.

Most small family businesses operate in informal ways. Thus, it is imperative for family business advisors and those who interact with them (such as key suppliers) to find ways to engage with the younger generation in the business as early as possible. A successful succession process requires strategic decision making and planning on the part of the incumbent and the successor. Business advisors such as bankers as well as key suppliers can play a significant role in this process not only to ensure a smooth transition between generations but also so that they can retain the family business as a customer. This will enable continued engagement and customer loyalty on the part of these agents, while ensuring a smoother transition for the family business.

Moreover, these results showed a strong role for capital in determining the transfer-readiness of businesses. Small businesses should therefore engage in early financial planning and continue to revisit the financial position of the business to enable eventual transition. This result suggests that building capital is a possible strategy to enable multi-generational involvement in the business that ultimately produces a successful business succession. In small and medium-scale businesses, funding two generations could require specific financial planning, expansion, or unique funding methods. Two generations could be involved in the business for multiple reasons: the incumbent generation could be training the successor and both actively working in the business, the incumbent generation could be in the business to help the successor in the capacity of a consultant, or the incumbent could need resources/funding from the business to allow for retirement. 


\section{References}

Barrett, M. 2014. Theories to define and understand family firms. In: H. Hasan (eds.) Being practical with theory: a window into business research. University of Wollongong, Wollongong, Australia, pp. 168-170.

Boyd, B., I.C. Botero and T. Fediuk. 2014. Incumbent decisions about succession transitions in family firms: a conceptual model. International Journal of Financial Studies 2: 335-358. https://doi.org/10.3390/ ijfs2040335

Calus, M. and G. Van Huylenbroeck. 2008. The succession effect within management decisions of family farms. Presented at the $12^{\text {th }}$ Congress of the European Association of Agricultural Economists EAAE 2008. August 26-29, 2008. Ghent, Belgium.

Danes, S.M., J. Lee, K. Stafford and R.K.Z. Heck. 2008. The effects of ethnicity, families and culture on entrepreneurial experience: an extension of sustainable family business theory. Journal of Developmental Entrepreneurship 13(3): 229-268.

De Massis, A., J.H. Chua and J.J. Chrisman. 2008. Factors preventing intra-family succession. Family Business Review 21(2): 183-199. https://doi.org/10.1111/j.1741-6248.2008.00118.x

Duffy, M., J. Baker and A. Lamberti. 2006. Iowa farmers' business and transfer plans. Iowa State University Extension and Outreach, Iowa City, IA, USA. Available at https://www.extension.iastate.edu/bfc/ files/page/files/IA\%20Farm\%20Business\%20survey\%20results.pdf

Family Enterprise USA (FEUSA). 2011. Annual survey of family firms. FEUSA, Minneapolis, MN, USA. Available at: https://familyenterpriseusa.com/wp-content/uploads/2016/02/FEUSA-Annual-Surveyof-Family-Firms-Key-Take-A-Ways-2011-2012-2013.pdf

Giraud, D. and R.J. Baker. 2005. Farm and ranch succession in a rural California county: extending the farm transfer project. Paper presented at the Annual Meeting of the Rural Sociological Society. August 11, 2005. Tampa, FL, USA.

Glauben, T., H. Tietje and C. Weiss. 2004. Succession in agriculture: a probit and a competing risk analysis. Selected paper for the annual Meeting of the American Agricultural Economist Association (AAEA). August 1-4, 2004. Denver, CO, USA.

Harveston, P., P. Davis and J. Lyden. 1997. Succession planning in family business: the impact of owner gender. Family Business Review 10(4): 373-396.

Kimhi, A., Y. Kislev and S. Abel. 1995. Intergenerational succession in Israeli family farms: 1971-1988. In: Y. Kislev, A. Kimhi and R. Lopez (eds.) Intergenerational transfers of farmers in different institutional environments. United States-Israel Binational Agricultural Research and Development Fund, Rishon LeZion, Israel.

Lange, K., J. Johnson, P. Johnson, D. Hudson and E.J. Belasco. 2011. Parental motivation in family farm intergenerational transfers. Poster prepared for presentation at the Agricultural \& Applied Economics Association's 2011 AAEA \& NAREA Joint Annual Meeting. July 24-26, 2011. Pittsburgh, PA, USA.

Li, C., D. Poskitt and X. Zhao. 2016. The bivariate probit model, maximum likelihood estimation, pseudo true parameters and partial identification. Monash Econometrics and Business Statistics Working Paper 16/16. Monash University Business School, Melbourne, Australia.

Lissoni, J., M. Pereira, M. Almeida and F. Serra. 2010. Family business: how family and ownership shapes business professionalization. Revista Brasileira de Gestao de Negocios 12(37): 464-479.

Martin-Reyna, J.M. and A.J. Duran-Encalada. 2015. Effects of family ownership, debt and board composition on Mexican firms performance. International Journal of Financial Studies 3: 56-74. https://doi. org/10.3390/ijfs3010056

Memili, E. and K. Misra. 2015. Performance and behavior of family firms. International Journal of Financial Studies 3(3): 194-229. https://doi.org/10.3390/ijfs3030194

Miller, D., I. Le Breton-Miller and H.R. Lester. 2013. Family firm governance, strategic conformity, and performance: institutional vs. strategic perspectives. Organization Science 24(1): 189-209. https:// doi.org/10.1287/orsc. 1110.0728

Miller, D., I. Le Breton-Miller. H.R. Lester and A.A. Cannella. 2007. Are family firms really superior performers? Journal of Corporate Finance 13(5): 829-858. https://doi.org/10.1016/j.jcorpfin.2007.03.004 
Mincer, J. 1993. Education and unemployment of women. Studies in human capital. Elgar Publishers, Cheltenham, UK.

Mishra, K.A., S.E. Hisham and S. Shaik. 2010. Succession decisions in U.S. family farm businesses. Journal of Agricultural and Resource Economics 35(1): 133-152.

Moon, E. 2019. Women own half the farmland in America. They don't earn half the profits. PacificStandard, May 15, 2019. Available at: https://psmag.com/economics/women-own-half-the-farmland-in-americathey-dont-earn-half-the-profits

Musselman, R.D. 2015. Stages of succession planning and factors of transferring management and ownership for the family agribusiness. MSc-thesis, Department of Agricultural Economics, Purdue University, IN, USA.

Pieper, T., J. Astrachan and G. Manners. 2013. Conflict in family business: common metaphors and suggestions for intervention. Interdisciplinary Journal of Applied Family Studies 62: 490-500.

Poza, J.E. and S.M. Daugherty. 2010. Family business, $3^{\text {rd }}$ edition. South-Western Cengage Learning, Boston, MA, USA.

Ramadani, V. and F. Hoy. 2015. Context and uniqueness of family businesses. In: D. Leo-Paul and V. Ramadani (eds.) Family businesses in transition economies. Springer, Cham, Switzerland. https:// doi.org/10.1007/978-3-319-14209-8_2

Saan, R., B. John and K. Samad. 2013. Succession planning and family-owned business continuity in the Wa municipality. International Journal of Innovative Research and Development 2(10): 304-309.

Smilkstein, G., C. Ashworth and D. Montano. 1982. Validity and reliability of the family APGAR as a test of family function. The Journal of Family Practice 15: 303-311.

Stafford, K., K.A. Duncan, S. Dane and M. Winter. 1999. A research model of sustainable family businesses. Family Business Review 12(3): 197-208.

Stavrou, E.T. and P.M. Swiercz. 1998. Securing the future of the family enterprise: a model of offspring intentions to join business. Entrepreneurship Theory and Practice 23(2): 19-40. https://doi. org/10.1177/104225879802300202

Sund, L, L. Melin and K. Haag. 2015. Intergenerational ownership succession: shifting the focus from outcome measurements to preparatory requirements. Journal of Family Business Strategy 6: 166-177.

Tagiuri, R. and J. Davis. 1996. Bivalent attributes of the family firm. Family Business Review 9(2): 199-208.

Venter, E., C. Boshoff and G. Maas. 2005. The influence of successor-related factors on the succession process in small and medium-sized family businesses. Family Business Review 18(4): 283-303.

Walsh, G. 2011. Family business succession: managing the all-important family component. KPMG, Amstelveen, the Netherlands. Available at: https://assets.kpmg/content/dam/kpmg/pdf/2015/07/3468succession.pdf

Warnar, P. 2012. Family businesses and knowledge transfer. MSc-thesis, Management of Technology, Delft University of Technology, Delft, the Netherlands.

Wiatt, R.D, M.I Marshall and R. Musselman. 2019. Management and ownership transfer: the case of midwestern family businesses. Presented at the Small Business Institute Conference. February 14-16, 2019. Orlando, FL, USA, pp. 52-68.

Wiatt, R.D. and M.I. Marshall. 2017a. Selecting a successor: the case of small- and medium- sized midwestern farms. In: A.K. Mishra, D. Viaggi and S. Gomez y Paloma (eds.) Public policy in agriculture: its impact on labor supply and household income. Routledge, London, UK, pp. 277-292.

Wiatt, R.D. and M.I. Marshall. 2017b. FB-BRAG: a tool for assessing family business functioning. Journal of Extension 55(5): 5TOT10. 